Robert R. Hammond, Anthony C. Webster aSC MB CHB FFARCS FRCPC

\title{
Haemodynamic effects of induction of epidural analgesia in labour
}

The effect of induction of epidural analgesia with 0.5 per cent bupivicaine on maternal haemodynamics was investigated in 21 patients with uncomplicated full-term pregnancies in early labour. Stroke volume, heart rate, and cardiac output $(S V, H R$, and $C O$ ) were measured by transcutaneous aortovelography (TAV). Systolic, diastolic, and mean arterial blood pressures (SBP. DNP, and $M A P$ ) were measured by indirect automatic oscillometry. Measurements were made with the patient in the left lateral decubitus position before and after an intravenous bolus of $500 \mathrm{ml}$ of lactated Ringer's solution preceding induction of epidural amalgesia, and again 30 and 45 minutes after induction. The $500 \mathrm{ml}$ bolus of lactated Ringer's solution did not prevent fall of $C O$ and $B P$ measured 30 minutes after induction, when there were statistically significant decreases in Co and cardiac index $(-10.2$ and -10.6 per cent, $p<0.05)$. and in $S B P, D B P$, and MAP $(-9.7,-12.5$, and -11.9 per cent. $p<0.005, p<0.005$ and $p<0.01$ respectively). At 45 minutes after induction, $C O$ and cardiac index had returned to baseline values. Although the decreases in SDP and DBP persisted, the change in MAP was not statistically significant.

Impairment of uterine blood flow (UBF) during labour is an important cause of fetal asphyxia and neonatal mortality and morbidity. Direct measurement of UBF in humans, requiring either vascular cannulation or radio-isotope techniques, is limited by ethical considerations. Since UBF is a component of maternal cardiac output ( $\mathrm{CO}$ ), investigation of the relationships between maternal $\mathrm{CO}$ and blood pressure (BP) is central to understanding the factors which influence uterine blood flow and placental perfusion during pregnancy and parturition.

Haemodynamic investigation of the normal parturient has been restricted by the practical and ethical limitations

\section{Key words}

ANAESTHESIA: obstetric; MEASUREMENT: blood pressure, cardiac output; ANAESTHETIC TECHNIQUES, REGIONAL: epidural.

From the Department of Anaesthesia, St. Joseph's Hospital, London, Ontario, N6A 4V2. Address correspondence to: Dr. Webster. of invasive methods to small series of cases. Furthermore, rapidly changing haemodynamic events such as those associated with pain, uterine contractions and fluid loading, cannot be followed adequately by the infrequent measurements provided by invasive techniques. It is not surprising that results have been some what inconsistent.

There is, however, consensus on the adverse effects of the supine position on the matemal circulation from inferior vena caval compression, ${ }^{1-3}$ and on uteroplacental perfusion in maternal hypotensive states from aortic compression caused by the full-term gravid uterus. ${ }^{4}$ It appears also that increases in cardiac output reported in the first and second stages of labour are more determined by tachycardia associated with pain, than by increases in stroke volume. ${ }^{5,6}$

The objective of this study was to investigate by the non-invasive techniques of transcutaneous aortovelog. raphy $^{7.8,9}$ and automatic electronic oscillometry, changes in maternal cardiac output and arterial blood pressure associated with induction of epidural analgesia in normal labour.

\section{Methods}

Twenty-one healthy patients with uncomplicated fullterm pregnancies expected to deliver vaginally, including one with twin pregnancy, were studied according to a protocol approved by the Health Sciences Committee on Human Research of the University of Western Ontario. They were selected on the basis of convenience, that is, daytime hours and availability of investigators and consent. Four sets of measurements of six cardiovascular parameters (CO, SV, HR, SBP, DBP, and MAP) were made on each subject. The first measurements were made in the latent phase of first stage of labour (baseline), when regular contractions and cervical dilatation had begun. The second set of measurements were made after intravenous infusion of $500 \mathrm{ml}$ of lactated Ringer's solution given immediately before induction of epidural analgesia. The third and fourth sets werc then made 30 and 45 minutes respectively after induction.

The study was conducted according to current standards of clinical care, thus precluding a control series without fluid loading. Because cardiac autput measurements required substantial patient cooperation at a time of 
physical and emotional stress, their number was minimised to that necessary to achieve the objective of the study. The post-induction measurements were made 30 minutes after induction, when maximum pain relief was obtained, and at $\mathbf{4 5}$ minutes when a steady state had been achieved.

All measurements were made between contractions with the patient horizontal in the left lateral position. Epidural analgesia was induced by different staff anaesthetists and residents. The local anaesthetic used was bupivicaine 0.5 per cent, and the dosage was between 7 and $10 \mathrm{ml}$. The sensory level of analgesia to pin prick was determined in the mid anterior and mid lateral lines at five-minute intervals following induction.

Fetal heart rate was measured by auscultation twice in the ten minute period following induction and subsequently at 15 minute intervals.

Blood pressure was monitored using a Dinamap ${ }^{\bar{a}}$ Model 845 automatic electronic oscillometer, and cardiac output was measured with the UltraCOM ${ }^{\otimes}$ portable ultrasonic cardiac output computer (Lawrence Medical Systems). The technique is based on measurement of cross sectional area of the aortic root and mean velocity of blood flow in the ascending aorta.

Ascending aortic root diameter was measured just above the tip of the aortic valve, or just above the sinus of Valsalva, by A-mode echocardiography. Aortic diameter was measured several times prior to the first set of readings. When the same value had been obtained three times, this was stored in the computer for subsequent calculations.

Blood flow velocity was mcasured by detection of the change in frequency between emitted ultrasonic signals and reflected signals from moving red cells. To determine blood flow velocity, the Doppler transducer was placed in the suprasternal notch and directed behind the sternum towards the aortic valve so that the ultrasound signal was parallel to the flow of blood in the ascending aorta. The transducer was adjusted until the maximum signal: proportional to flow velocity was obtained, as indicated by a signal number displayed on the cathode ray tube and a corresponding audio signal generated by the computer. Blood flow velocity is calculated from the Doppler equation: $V=D f \times c / 2 f \times \operatorname{Cos} \theta$, where $V=$ magnitude of blood flow velocity; Df = the measured Doppler frequency shift; $f=$ the known frequency of the ultrasonic signal; $c=$ the speed of sound in tissue $(1,540 \mathrm{~m} / \mathrm{s})$; and $\theta=$ the angle between the direction of blood flow and the ultrasonic signal.

Blood flow velocity is calculated by integrating the area under the velocity curve. Stroke volume, heart rate and cardiac output are derived by the computer and the results are displayed on the cathode ray tube and by strip chart recorder. Proper direction of the Doppler transducers both for measurement of aortic diameter and blood flow velocity, necessary for accuracy, requires dexterity and practice. Several serial readings (from three to ten) were made during each measurement set to ensure consistency. For each set of measurements, the raw values used in the statistical analysis for cardiac output measurements were means of these serial readings.

Each patient's raw values for $\mathrm{Cl}, \mathrm{CO}, \mathrm{SV}, \mathrm{HR}, \mathrm{SBP}$, $\mathrm{DBP}$, and MAP, for each of the four measurement sets were subjected to a statistical analysis consisting of repeated measures analysis of variance, followed by Dunnett's t test for comparing means with a control. ${ }^{10}$

To determine the reliability of our cardiac output measurements, methodological and biological variability studics were conducted. The methodological variability study consisted of four measurements of $\mathrm{CO}$ spaced five minutes apart, performed in the left lateral position on three mothers with uncomplicated full-term pregnancies, prior to the beginning of labour. The biological variability study consisted of continuous serial measurements of $\mathrm{CO}$ for a period of 15 minutes between and during contractions on three mothers with uncomplicated full-term pregnancies in active labour with epidural analgesia, in the left lateral position with cervical dilatation of about 5 to $6 \mathrm{~cm}$.

Neonatal assessment was performed by the attending anaesthetist or resident according to routine clinical practice for uncomplicated delivery, that is by Apgar score at one and five minutes after birth.

\section{Results}

The mean age of the 21 subjects studied was 28.2 (SD \pm

TABLE I Methodological variabjlity (mean CO $\left(L \cdot \min ^{-1}\right)$ )

\begin{tabular}{llllllll}
\hline & \multicolumn{3}{l}{ Time taken (min) } & & & \multicolumn{2}{l}{ Within subject } \\
\cline { 2 - 3 } \cline { 6 - 8 } Subject \# & $T=0$ & $T=5$ & $T=10$ & $T=15$ & & Mean & Standard error \\
\hline 1 & 4.76 & 4.96 & 4.94 & 5.08 & & 4.94 & $0.13(2.6 \%)$ \\
2 & 5.78 & 5.04 & 5.10 & 5.24 & & 5.29 & $0.34(6.4 \%)$ \\
3 & 5.30 & 5.42 & 5.48 & 5.54 & & 5.44 & $0.10(1.8 \%)$ \\
& & & & & & & Mean SE $=3.6 \%$
\end{tabular}


TABLE II Biological variability (mean $\mathrm{CO}\left(\mathrm{L} \cdot \mathrm{min}^{-1}\right)$ )

\begin{tabular}{|c|c|c|c|c|}
\hline \multirow[b]{2}{*}{ Subject $\neq$} & \multirow{2}{*}{$\begin{array}{l}\text { Mean during } \\
\text { confractions }\end{array}$} & \multirow{2}{*}{$\begin{array}{l}\text { Mean between } \\
\text { contractions }\end{array}$} & \multicolumn{2}{|c|}{ Within subject } \\
\hline & & & Mean & Srandard error \\
\hline 1 & 4.49 & 4.60 & 4.55 & $0.078(1.7 \%)$ \\
\hline 2 & 8.46 & 8.41 & R_44 & $0.035(0.4 \%)$ \\
\hline \multirow[t]{2}{*}{3} & 5.63 & 5.42 & 5.53 & $0.148(2.7 \%)$ \\
\hline & & & \multicolumn{2}{|c|}{ Mean SE $=1.6 \%$} \\
\hline
\end{tabular}

$-3.4)$, and the mean height and weight were $162.1 \pm 6.7 \mathrm{~cm}$ and $72.9 \pm 7.8 \mathrm{~kg}$ respectively.

The mean standard error (within subjects) obtained in the methodological variability study was 3.6 per cent (Table I), and in the biological variability study was 1.6 per cent (Table II).

Table IIl gives the mean values at each measurement set with standard deviations in parentheses, and the percentage change from the baseline measurements for each cardiovascular parameter examined. The results of the four sets of measurements for cardiac output and mean arterial pressure are summarized in Figures 1 and 2 . Since central venous pressure was not measured, periphcral vascular resistance was approximated by dividing MAP by flow expressed as $\mathrm{ml}$ per second (peripheral resistance units (PRL)).

$\mathrm{CO}$ and $\mathrm{CI}$ measurements made 30 min after induction of epidural analgesia were significantly lower than those

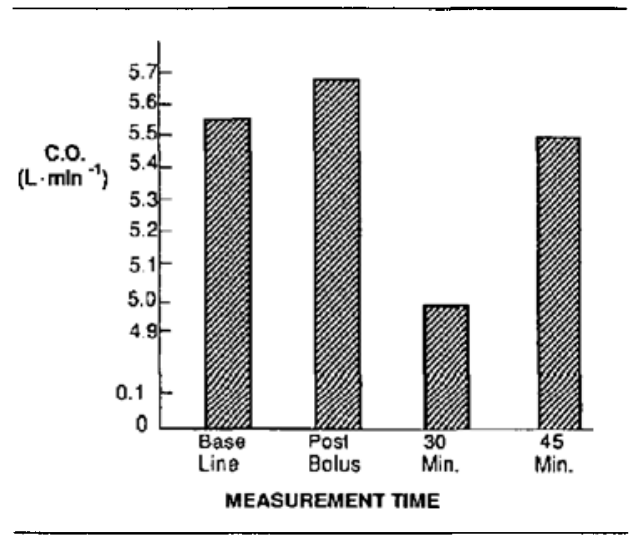

FIGURE 1 Cardiac output changes following IV fluid loading and at 30 and 45 minutes following induction of epidural analgesia.

made before induction, -10.2 and -10.6 per cent respectively, $p<0.05$, than those made after the intravenous infusion of a $500 \mathrm{ml}$ bolus of lactated Ringer's solution, and 45 min after induction. Stroke volume and heart rate were reduced in approximately equal proportions at 30 min compared with baseline and post-bolus.

SBP, DBP, and MAP, measured $30 \mathrm{~min}$ after induction of epidural analgesia were significantly lower $(-9.7$, -12.5 , and -11.9 per cent, $\mathrm{p}<0.005, \mathrm{p}<0.005$ and

TABLE III Cardiovascular paramelers (mean $=$ SD) and \% change from baseline values

\begin{tabular}{|c|c|c|c|c|}
\hline & Baseline & $\begin{array}{l}\text { Post fiuid } \\
\text { Bolus }\end{array}$ & $\begin{array}{l}30 \mathrm{~min} \\
\text { post EPID }\end{array}$ & $\begin{array}{l}45 \min \\
\text { post } E P I D\end{array}$ \\
\hline $\mathrm{CI}\left(\mathrm{L} \cdot \mathrm{min}^{-1} \cdot \mathrm{m}^{-2}\right)$ & $3.11 \pm 0.81$ & $\begin{array}{r}3.19 \pm 0.98 \\
+2.6 \%\end{array}$ & $\begin{array}{r}2.78 \pm 0.69 * \\
-10.6 \% *\end{array}$ & $\begin{aligned} & 3.07 \pm 0.96 \\
&-1.3 \%\end{aligned}$ \\
\hline $\operatorname{Co}\left(L \cdot \min ^{-1}\right)$ & $5.50 \pm 1.46$ & $\begin{array}{r}5.66 \pm 1.74 \\
+2.9 \%\end{array}$ & $\begin{array}{r}4.94 \pm 1.34^{t} \\
-10.2 \% *\end{array}$ & $\begin{array}{l}5.46 \pm 1.81 \\
-0.7 \%\end{array}$ \\
\hline $\mathrm{SV}(\mathrm{ml})$ & $73.7 \pm 20.9$ & $\begin{array}{l}75.5 \pm 24.0 \\
+2.4 \%\end{array}$ & $\begin{array}{l}69.6 \pm 20.3 \\
-5.5 \%\end{array}$ & $\begin{array}{l}74.5 \pm 22.9 \\
-1.1 \%\end{array}$ \\
\hline HR (bears' $\mathrm{min}^{-1}$ ) & $76.1 \pm 11.6$ & $\begin{array}{l}77.1 \pm 12.1 \\
+1.3 \%\end{array}$ & $\begin{array}{l}72.5 \pm 8.7 \\
-4.7 \%\end{array}$ & $\begin{array}{l}74.3 \pm 12.3 \\
-2.4 \%\end{array}$ \\
\hline $\mathrm{SBP}(\mathrm{mmHg})$ & $116.2 \pm 13.2$ & $\begin{array}{l}118.3 \pm 12.6 \\
+1.8 \%\end{array}$ & $\begin{array}{l}104.9 \pm 10.9 \div \\
-9.7 \% \neq\end{array}$ & $\begin{array}{l}106.3 \pm 12.3+ \\
-8.5 \% \neq\end{array}$ \\
\hline DBP (mmHg) & $68.7=13.6$ & $\begin{array}{l}66.3=11.3 \\
-3.5 \%\end{array}$ & $\begin{array}{l}60.1 \pm 11.5 \ddagger \\
-12.5 \% \neq\end{array}$ & $\begin{array}{l}59.5 \pm 11.1 \neq \\
-13.4 \%\end{array}$ \\
\hline $\mathrm{MAP}(\mathrm{mmHg})$ & $81.6 \pm 15.2$ & $\begin{array}{l}84.1 \pm 13.6 \\
+3.1 \%\end{array}$ & $\begin{array}{r}71.9+10.9 \dagger \\
-11.9 \% \div\end{array}$ & $\begin{array}{l}74.8 \pm 10.0 \\
-8.3 \%\end{array}$ \\
\hline PRU & 0.89 & 0.89 & 0.87 & 0.82 \\
\hline
\end{tabular}

${ }^{*} p<0.05 . t_{p}<0.01 . \neq_{p}<0.005$. 


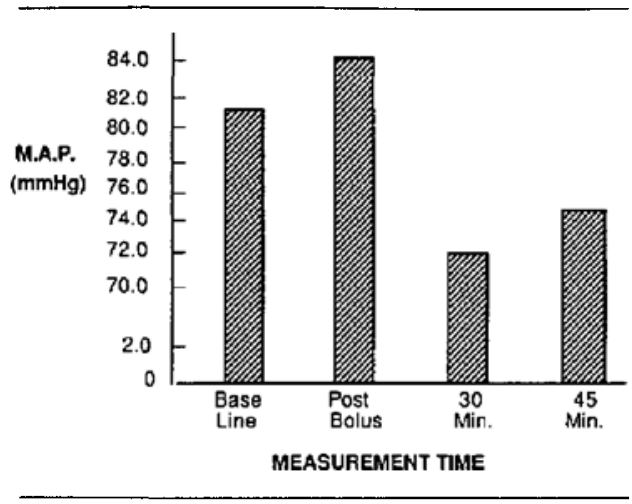

FIGURE 2 Mean arterial pressure changes following IV fluid loading and at 30 and 45 minutes following induction of epidural analgesia

$\mathrm{p}<0.01$ respectively), than those made before induction and after the $500 \mathrm{ml}$ bolus of lactated Ringer's solution. At 45 minutes after induction, although decrease in SDP and DBP persisted, the change in MAP compared with baseline values was not statistically significant.

There was no abnormality in fetal heart rate in the series. Deliveries were either by uncomplicated outlet forceps or spontaneous. Nineteen of the 22 infants had 5 min Apgar scores of 9 or 10 . Three infants, including the second Apgar score of 8 . Of the six parturients with a fall in cardiac output $>20$ per cent, two infants had Apgar scores of $8 / 9$ and $7 / 8$. Of the seven parturients with a fall in MAP $>20$ per cent, only the twins had low Apgar scores (7/9 and 1/8) (Table IV). All infants were subsequently assessed as normal by neonatology staff and discharged from hospital with the mother.

\section{Discussion}

Of the methods of cardiac output measurement now

TABLE IV $\Lambda$ pgar scores of babies of mothers with fall in cardice output and MAP $>20 \%$

\begin{tabular}{llll}
\hline Subject \# & Apgar score & $C O$ & MAP \\
\hline 5 & $9 / 10$ & $-37 \%$ & \\
6 & $9 / 9$ & $-23 \%$ & \\
7 & $9 / 9$ & & $-23 \%$ \\
8 & $9 / 9$ & & $-20 \%$ \\
5 & $7 / 9: 1 / 8$ & & $-29 \%$ \\
11 & $9 / 10$ & & $-20 \%$ \\
14 & $9 / 9$ & $-25 \%$ & $-43 \%$ \\
15 & $8 / 9$ & $-23 \%$ & \\
17 & $9 / 10$ & & $-31 \%$ \\
18 & $9 / 9$ & & $-42 \%$ \\
20 & $7 / 8$ & $-38 \%$ & \\
21 & $9 / 9$ & $-31 \%$ & \\
\hline
\end{tabular}

available, cchocardiography requires special technical skill and normal ventricular function. Soluble gas uptake methods are time-consuming and cannot give rapid serial results. Impedance cardiography has theoretical actvantages of claimed reproducibility, technical ease and continuous serial measurement, but reports are sparse of its use in obstetrics. ${ }^{11-13}$

Measurement of cardiac output by transcutaneous aortovelography has been compared with other methods. Excellent correlation with thermodilution cardiac output has been achieved with correlation cocfficients of 0.97 ( $\mathrm{p}<0.001$ ) reported in one study, and 0.94 in another. ${ }^{14.15}$ Doppler methods have been found to compare approximatcly as well with other cardiac output measurements, indicator dye, direct Fick, and thermodilution, as these methods compare among themselves. ${ }^{16}$ Transcutaneous aortovelography does, however, require technical skill, and the need for patient immability and cooperation during measurement limits its usefulness during labour.

Adequate epidural analgesia in the first stage of labour requires afferent sympathetic blockade to the level of tenth thoracic dermatome. Since this is accompanied by sympathetic efferent blockade and since absolute accuracy in segmental level of blockade is not always achieved, haemodynamic instability from loss of normal sympathetic regulation proportional to the extent of sympathetic. denervation, is a major potential hazard.

The immediate matemal haemodynamic effect of sympalhetic efferent blockade is vasodilatation in resistance and capacitance vessels. Sympathetic afferent blockade in labour, by abolition of the reflex tachycardia that accompanies pain, tends to reduce maternal heart rate. The effect on cardiac output is the resultant of these influences; the first would increase cardiac outpur by facilitating venous return, whereas the others would diminish it by reducing venous return and heart rate. In clinical practice, haemodynamic instability is reflected in maternal hypotension. Prophylactic measures include avoidance of unnecessarily high blockade, intravenous fluid loading and maintenance of the lateral position to avoid vena caval compression.

Our results suggest that significant maternal hypotension and reduction in cardiac output is not prevented by a pre-induction bolus of $500 \mathrm{ml}$ of lactated Ringer's solution. It may be postulated that, for fluid loading to be more effective, larger extracellular fluid volume expansion is necessary. Assuming that total body water is about 60 per cent of body weight, and that about 45 per cent of TBW is extracellular, and that an intravenous infusion rapidly equilibrates throughout the ECF compartment, in an average $70 \mathrm{~kg}$ individual a $500 \mathrm{ml}$ IV bolus of lactated Ringer's solution represents about a two per cent expansion of ECF volume.

Reduction in $\mathrm{CO}$ at 30 minutes after induction of 
epidural analgesia with approximately equal reductions in $\mathrm{SV}$ and $\mathrm{HR}$, suggests that reduction in venous return from increased venous capacitance is compounded by diminished heart rate coinciding with pain relief. Return of cardiac output approximately to baseline values at 45 minutes with a reduction in MAP and PRU that are not statistically significant, suggests restoration of venous return and partial haemodynamic compensation.

Reduction in maternal cardiac output and blood pressure noted following induction of epidural analgesit were not accompanied by fetal heart rate abnormalities or impaired fetal outcome. According to current standards of clinical care, reduction of maternal systolic blood pressure $>20$ per cent was treated by increasing the rate of the intravenous infusion and administration of oxygen by face mask, with the patient remaining in the lateral decubitus position. No patient required vasopressor therapy

Deternination of the precise segmental level of analgesia was obscurcd by side to side variability of up to three or four dermatomal levels in many individuats, influenced by the side on which epidural analgesia had been induced, so that simple comparison between subjects was not possible. At 30 min, all patients were entirely pain free, and the average level of analgesia to pin prick was $\mathbf{T}_{10}$. In no case was the level of blockade higher than $T_{7}$, and in those cases with a fall in $\mathrm{CO}$ and MAP $>20$ per cent, the number of patients with spread beyond $T_{10}$ was too small for analysis.

Our results emphasize the importance in clinical practice of frequent monitoring of maternal blood pressure and fetal heart rate following induction of epidural analgesia in labour, and suggest the need to examine the effect of more aggressive intravenous fluid loading in prophylaxis of its potentially deleterious haemodynamic consequences.

\section{Acknowledgements}

The authors acknowledge with thanks the P.S.I. Foundation for financial support, Dr. I. Challis, Director, The Research Institute, St. Joseph's Hospital for guidance, Dr. W. A. Tweed for advice in preparing the manuscript, Larry Stitt, M.Sc., Stalab, U.W.O., for stutistical assistance, and the nursing staff, obstetricians and anaesthetists of St. Joseph's Hospital for their cooperation.

\section{References}

1 Lees $M M$, Taylor $S H$. Scont DB. A study of cardiac output at rest throughout pregnancy. J Obstet Gynaecol Br Commonw 1967; 74: 319.

2 Lees, MM, Scon DB, Kerr MG. The circulatory effects of recumbant postural change in late pregnancy. Cin Sci $1967 ; 32: 453$
3 Lees, $M M$, Scot $D B, K e r r M G$. Haemodynamic changes associated with labour. J Obstet Gynaecol Br Commonw $1970 ; 77: 29$.

4 Bieniarz J, Maqued AE, Caldeyro-Barcia R. Compression of aorta by uterus in late pregnancy. 1 . Variations between femoral and brachial artery pressure with changes from hypertension to hypotension. Am J Obst Gynecol 1966; 95: 795 .

5 Uieland K. Hansen JM. Maternal cardiovascular dynamics. Ill. Labour and delivery under local and caudal analgesia. Am J Obst Gynecol 1969; 103: 8.

6 Hansen $J M$, Veland $K$. The influence of caudal analgesia on cardiovascular dynamies during labour and delivery. Acta Anesthesiol Scand (Suppl) 1966; 23: 499-52.

7 Newman $B$. Cardiac output changes during Caesarean section. Measurements by transcutaneous aortovelography. Anaesthesia 1982; 37: 270.

8 Newmon $B$, Derrington $C$, Dore $C$. Cardiac output and the recumbent position in late pregnancy. Anaesthesia 1983; 38: 332 .

9 Backe B, Brodrkorb CJ, Giltvedr J et al. Fernl and maternal aortic flow in two different maternal positions. An investigation with combined Doppler-velocimetry and ultrasonic multiple array. Ultrasaund Med Biol 1983; 9: 587.

10 Winer B.I. Statistical Principles in Experimental Design. 2nd Ed. New York, McGraw-Hill, 1971

11 Milsom I, Forssman L, Sivertsson R, Dottori $O$. Measure ment of cardiac stroke volume by impedance cardiography in the last trimester of pregnancy. Acta Obstet Gynecol Scand. $1983 ; 62: 473$.

12 Milsom I, Forssman L. Biber B, Dottori O, Sivertsson R. Measurement of cardiac stroke volume during Caesarean section; a comparison between impedance cardiography and the dye dilution technique. Acta Araesthesiol Scand 1983; 27: 421 .

13 Myhrman $P$, Granerus $G$, Karlsson $K$, Lundgren. Cardiac output in normal pregnancy measured by impedance cardiography. Scand J Clin Lab Invest 1982; 42 : 513

14 Chandraratna AP et al. Determination of cardiac output by transcutaneous continuous-wave ultrasonic doppler computer. Am J Cardiol 1984; 53: 234.

15 Hurtsman $L L$ et al. Non-invasive doppler determination of cardiac output in man; clinical validation. Circulation 1983; 67: 593 .

16 Schuster $A H, N o n d a N C$. Doppler echocardiographic measurement of cardiac output: comparison with a nongolden standard. Am J Curdiol 1984; \$3: 257. 


\section{Résựẹ́}

L'effet de l'induction ae l'analgésie épidurale avec 0.5 pour cent de bupivacaine sur l'hémodynamique maternelle a été investigué chez 21 patientes au début du travail lors d'une grossesse à terme non compliquée. Le volume d'ejection, la fréquence cardiaque, et débit cardiaque ( $S V, H R$, ei CO) ant été mesurés par cortovélographie transcutanée (TAVI. La pression artérielle systolique et diastolique et moycnne (SBP, DBP, et MAP Jant été mesurées par oscillométrie automatique indirecte. Les mesures ont été faites avec la patiente en décubitus latéral gauche avant et après un bolus intraveineux de $500 \mathrm{ml}$ de lactate Ringer avant l' induction de "amalgésie épidurale et aussi 30 et 45 minudes après l' induction. L'injection de $500 \mathrm{ml}$ de solution de lactate Ringer n'a pas empéché la chute du CO et du BP mesurés 30 minutes après l'induction lorsqu'it y avait une diminution statistiquement significative du CO et de l'index cardiaque $(-10.2$ et -10.6 pour cent, $p<0.05)$, et de la MAP $(-11.2$ pour cent, $p<0.01)$. Quarante-cinq minutes après l'induction, le $\mathrm{CO}$ et l'index cardiaque sont retourrés aux valeurs de base et l'évaluation de la MAP n'était pas statistiquement significative. 